\title{
Biological factor related to Asian sand dust particles contributes to the exacerbation of asthma
}

\section{$\operatorname{AUTHOR}(\mathrm{S})$ :}

Honda, Akiko; Sawahara, Takahiro; Hayashi, Tomohiro; Tsuji, Kenshi; Fukushima, Wataru; Oishi, Mizuki; Kitamura, Gaku; ... Ichinose, Takamichi; Ueda, Kayo; Takano, Hirohisa

\section{CITATION:}

Honda, Akiko ...[et al]. Biological factor related to Asian sand dust particles contributes to the exacerbation of asthma. Journal of Applied Toxicology 2017, 37(5): 583-590

\section{ISSUE DATE:}

2017-05

URL:

http://hdl.handle.net/2433/243825

\section{RIGHT:}

This is the peer reviewed version of the following article: 'Journal of Applied Toxicology' 37(5) 583-590, which has been published in final form at https://doi.org/10.1002/jat.3395. This article may be used for non-commercial purposes in accordance with Wiley Terms and Conditions for Use of Self-Archived Versions.; The full-text file will be made open to the public on 27 March 2018 in accordance with publisher's 'Terms and Conditions for Self-Archiving'.; この論文は出版 社版でありません。引用の際には出版社版をご確認ご利用ください。; This is not the published version. Please cite only the published version. 
Research Article

\title{
Biological factor related to Asian sand dust particles contributes to the exacerbation of asthma
}

\author{
Akiko Honda ${ }^{\mathrm{a}, *}$, Takahiro Sawahara ${ }^{\mathrm{a}}$, Tomohiro Hayashi ${ }^{\mathrm{a}}$, Kenshi Tsuji ${ }^{\mathrm{a}}$, \\ Wataru Fukushima ${ }^{\mathrm{a}}$, Mizuki Oishi ${ }^{\mathrm{a}}$, Gaku Kitamura ${ }^{\mathrm{a}}$, Hitomi Kudo ${ }^{\mathrm{a}}$, Sho Ito ${ }^{\mathrm{a}}$, \\ Seiichi Yoshida ${ }^{\mathrm{b}}$, Takamichi Ichinose ${ }^{\mathrm{b}}$, Kayo Ueda ${ }^{\mathrm{a}}$, and Hirohisa Takano ${ }^{\mathrm{a}}$
}

a Environmental Health Division, Department of Environmental Engineering, Graduate School of Engineering, Kyoto University. Kyoto, Japan

${ }^{\mathrm{b}}$ Department of Health Sciences, Oita University of Nursing and Health Sciences, Oita, Japan

Running title: Biological factor related to Asian sand dust particles affects asthma

*Corresponding author: Dr. Akiko Honda, Environmental Health Division, Department of Environmental Engineering, Graduate School of Engineering, Kyoto University, C Cluster, Kyoto-Daigaku-Katsura, Nishikyo-ku, Kyoto 615-8540, Japan.

Phone: +81-75-383-3345; Fax: +81-75-383-3344. E-mail: akko@health.env.kyoto-u.ac.jp 


\section{Abstract}

Epidemiologic studies have revealed that Asian sand dust particles (ASDs) can affect respiratory and immune health represented by asthma. The factors that are responsible for the exacerbation of asthma remain unclear. The fungus Bjerkandera adusta (B.ad) and polycyclic aromatic hydrocarbons (PAHs) such as benzo[a]pyrene (BaP) have been identified in ASDs collected from the atmosphere when an ASD event occurred. We investigated the effects of B.ad and $\mathrm{BaP}$ related to ASDs on respiratory and immune systems. Bone marrow-derived antigen presenting cells (APCs) and splenocytes from atopic prone NC/Nga mice and human airway epithelial cells were exposed to the B.ad or to $\mathrm{BaP}$ in the presence and absence of heated-ASDs (H-ASDs). Both B.ad and BaP in both the presence and absence of H-ASDs increased the expression of cell surface molecules on APCs. H-ASDs alone slightly activated APCs. The expressions induced by B.ad were higher than those induced by $\mathrm{BaP}$ in the presence and absence of H-ASDs. There were no remarkable effects on the activation of splenocytes or the pro-inflammatory responses in airway epithelial cells. These results suggest that B.ad rather than $\mathrm{BaP}$ contributes to the exacerbation of asthma regardless of the presence or absence of sand particles, especially by the activation of the immune system via APCs.

Key Words: Asian sand dust particles, Bjerkandera adusta, Benzo[a]pyrene, Bone-marrowderived antigen presenting cells, Asthma 


\section{Short Abstract for the Table of Contents}

Bjerkandera adusta (B.ad) and benzo[a]pyrene (BaP) each activated antigen presenting cells (APCs) in the presence and the absence of heated Asian sand dust particles (H-ASDs). H-ASDs alone slightly activated APCs. The activation induced by B.ad was more apparent than that by $\mathrm{BaP}$ in the presence and absence of H-ASDs. B.ad rather than $\mathrm{BaP}$ contributes to the exacerbation of asthma regardless of the presence or absence of sand particles, especially by the activation of the immune system via APCs. 


\section{Introduction}

Sand dust storms have adverse health effects on a global scale because they can be transported over a long distance [Esmaeil et al. 2014]. For example, Asian sand dust particles (ASDs) have spread over large areas, including East China, the Korean peninsula, Taiwan, and Japan. Several epidemiological studies suggested that exposure to ASDs can increase daily mortality, cardiovascular and respiratory diseases [Chen et al. 2004; Kwon et al. 2002; Hashizume et al. 2010; Ueda et al. 2012].

The exacerbation of respiratory diseases such as asthma by ASDs is a public health problem. It has been reported that ASD events have been associated with an increased risk in hospitalizations for asthma and the worsening of asthma [Kanatani et al. 2010; Watanabe et al. 2011]. Experimental studies demonstrated that repeated airway exposure of mice to ASDs contributed to the exacerbation of lung inflammation in the presence of an allergen such as ovalbumin (OVA) and dermatophagoides farinae [Hiyoshi et al. 2005; Ichinose et al. 2006]. ASDs can also affect respiratory and immune systems. In brief, ASDs caused a proinflammatory response via interleukin (IL)-6 and IL-8 production from airway epithelial cells, induced the maturation and activation of bone marrow-derived antigen presenting cells (APCs), and increased the proliferation of splenocytes [Honda et al. 2014].

We have suggested that not only dust particles themselves but also components related to ASDs may cause adverse health effects [Honda et al. 2014]. However, the responsible factors 
that lead to the exacerbation of respiratory and immune diseases remain unclear.

ASDs are composed mainly of silicon, aluminum, calcium, and iron. They also contain various biological and chemical materials such as fungi and polycyclic aromatic hydrocarbons (PAHs) [Ho et al. 2005; Lee et al. 2009; Maki et al. 2008, 2010; Mori et al. 2002, 2003; Tamamura et al. 2007; Wu et al. 2004; Yeo and Kim 2002]. In Japan, the fungus Bjerkandera adusta (B.ad) has been identified in ASDs collected from the atmosphere when an ASD event occurred [Kobayashi et al. 2010]. It was reported that B.ad induces respiratory problems such as allergic cough [Ogawa et al. 2009, 2011]. He et al. [2012, 2016] reported that co-exposure to heated-ASDs (H-ASDs) and B.ad aggravated lung eosinophilia via marked increases in proinflammatory mediators in both the presence and absence of OVA. It was also reported that HASDs with organic chemicals containing PAH exacerbated OVA-induced lung eosinophilia via increases in Th2-mediated cytokines [Ren et al. 2014]. However, the degree of the contributions of biological and chemical factors and the underlying mechanisms by which these factors contribute to respiratory diseases have not been clarified.

In the present study, we compared the effects of biological and chemical factors related to ASDs on immune cells from atopy-prone NC/Nga mice and human airway epithelial cells. We focused on B.ad as a biological factor and benzo[a]pyrene $(\mathrm{BaP})$ as a chemical factor. Our purpose was to investigate the difference of contributions of $\mathrm{B}$.ad and $\mathrm{BaP}$ to the respiratory and immune health degraded by ASDs. Our ultimate goals are to identify the responsible 
factors that lead to the exacerbation of respiratory and immune diseases represented by asthma and to determine the underlying mechanisms.

\section{Materials and methods}

Mice and preparation of bone marrow cells and splenocytes

Ten-week-old SPF NC/NgaTndCrlj male mice were purchased from Charles River Japan (Osaka, Japan). They were housed in an animal facility that was maintained at $24^{\circ}-26^{\circ} \mathrm{C}$ and a 12-h light/dark cycle under conventional conditions. The procedures of all animal studies were approved by the Animal Research Committee at Kyoto University. Mice were sacrificed by cervical dislocation and exsanguinated from the cut abdominal aorta and vein. After the surrounding muscle tissue was removed, the bones were left in $70 \%$ ethanol for 3 min and washed with RPMI1640 medium (Life Technologies, Carlsbad, CA). Both ends of the bones were cut, and the marrow was then flushed with RPMI1640 using a syringe with a 24G needle.

The marrow suspension was passed through sterile 250 nylon mesh to remove small pieces of bone and debris, and the red blood cells were lysed with BD PharmLyse (Becton Dickinson, Lincoln Park, NJ). The spleen was pushed through a sterile 200-mesh stainless steel sheet, and red blood cells were also lysed with BD PharmLyse. The cells were centrifuged at $400 \mathrm{~g}$ for $5 \mathrm{~min}$ at $20^{\circ} \mathrm{C}$. After being washed with RPMI 1640, the cells were resuspended in culture medium R10, which was RPMI 1640 supplemented with 10\% heat-inactivated fetal 
bovine serum (FBS; MP Biomedicals, Eschwege, Germany), $100 \mathrm{U} / \mathrm{mL}$ penicillin, $100 \mu \mathrm{g} / \mathrm{mL}$ streptomycin (Sigma, St. Louis, MO), and $50 \mu \mathrm{M}$ 2-mercaptoethanol (Life Technologies). The numbers of viable cells were determined by the trypan blue (Life Technologies) exclusion method.

Differentiation of bone marrow-derived APCs

APCs were differentiated using a modification of the protocol of Lutz et al. [1999]. In brief, bone marrow cells $\left(4 \times 10^{5} / \mathrm{mL}\right)$ were cultured in R10 medium $(10 \mathrm{~mL})$ containing 20 ng/mL granulocyte-macrophage colony-stimulating factor (GM-CSF). On day 3, the same volume of the medium containing $20 \mathrm{ng} / \mathrm{mL}$ GM-CSF was added to the culture. On day 6, half the culture medium was replaced with fresh medium. On day 8, non-adherent and loosely adherent cells were collected by gentle pipetting. The differentiated APCs were centrifuged at $400 \mathrm{~g}$ for $5 \mathrm{~min}$ at $20^{\circ} \mathrm{C}$ and then resuspended in fresh medium. The numbers of viable cells were determined by the trypan blue exclusion method.

Cell culture for airway epithelial cells

The BEAS-2B cell line, derived from human bronchial epithelial cells transformed by an adenovirus 12-SV40 hybrid virus, was purchased from the European Collection of Cell 
Cultures (Salisbury, Wiltshire, UK). The cells $\left(7.5 \times 10^{4}\right.$ cells $\left./ \mathrm{mL}\right)$ were seeded in 96 -well $(0.07$ $\mathrm{mL})$ or 12-well $(0.7 \mathrm{~mL})$ collagen I-coated plates and incubated for $72 \mathrm{~h}$ to reach semiconfluence in the serum free-medium LHC-9 (Life Technologies) at $37^{\circ} \mathrm{C}$ in a humidified atmosphere of $5 \% \mathrm{CO}_{2}$.

Preparation of ASDs, B.ad, and BaP

ASDs were collected from the Gobi Desert in north-east Asia (https://www.nies.go.jp/labo/crm-e/gobikosadust.html) and were certified as reference material by the National Institute for Environmental Studies, Japan (CRM No. 30). ASDs were treated by heating at $360^{\circ} \mathrm{C}$ for $30 \mathrm{~min}$ (H-ASDs) to exclude substances that are sensitive to heat. $\mathrm{H}$ ASDs were diluted to give a final concentration of $50 \mu \mathrm{g} / \mathrm{mL}$ in media. Our previous study showed that flying ASDs at the doses of $30-90 \mu \mathrm{g} / \mathrm{mL}$ caused interleukin (IL)-6 and IL-8 releases from airway epithelial cells, induced the maturation and activation of APCs, and increased the proliferation of splenocytes [Honda et al.2014]. About 10\% of flying ASDs was materials adhered to flying ASD. Therefore, H-ASDs at a dose of $50 \mu \mathrm{g} / \mathrm{mL}$ were used.

B.ad was prepared as described by He et al. [2016]. In brief, the B.ad was inactivated with $1 \%$ formalin for 1 day at $4^{\circ} \mathrm{C}$ and dissolved in saline. The suspension was sonicated for 1 min with a UD-201 type ultrasonic disrupter with a micro-tip (Tomy, Tokyo) under cooling conditions. Then the suspension was diluted in media (final concentration $2.5 \%$ saline). 
BaP (CAS.No 50-32-8, purity 98.0\%) was purchased from Sigma. BaP was dissolved in dimethyl sulfoxide (DMSO) and then diluted in media (final concentration 0.1\% DMSO).

\section{Experimental protocol}

APCs $\left(1 \times 10^{6}\right.$ cells/mL) from the NC/Nga mice were exposed to B.ad $(0,1,5$, or 25 $\mu \mathrm{g} / \mathrm{mL})$ or $\mathrm{BaP}(0,0.1,1$, or $10 \mu \mathrm{M})$ in the presence and absence of H-ASDs (50 $\mu \mathrm{g} / \mathrm{mL}$ ) for $24 \mathrm{~h}$. The final media volume was $1.2 \mathrm{~mL}$ (12-well plates) and $0.2 \mathrm{~mL}$ (96-well plates). The cluster of differentiation (CD) 86 and dendritic and epithelial cells (DEC)205 protein expressions on the cell surface were evaluated by a fluorescence-activated cell sorter (FACS).

Splenocytes $\left(1 \times 10^{6}\right.$ cells/mL) from the NC/Nga mice were exposed to B.ad $(0,1,5$, or $25 \mu \mathrm{g} / \mathrm{mL})$ or $\mathrm{BaP}(0,0.1,1$, or $10 \mu \mathrm{M})$ in the presence and absence of H-ASDs $(50 \mu \mathrm{g} / \mathrm{mL})$ for 24 or $72 \mathrm{~h}$. The final media volume was $1.2 \mathrm{~mL}$ (12-well plates) and $0.2 \mathrm{~mL}$ (96-well plates). The cell proliferation and the expression of $\mathrm{T}$ cell receptor (TCR) protein on the cell surface were evaluated by a 5-bromo-2'-deoxyuridine (BrdU) enzyme-linked immunosorbent assay (ELISA) and FACS, respectively.

After airway epithelial cells grew to semi-confluence in LHC-9, the cells were exposed to B.ad $(0,1,5$, or $25 \mu \mathrm{g} / \mathrm{mL})$ or $\mathrm{BaP}(0,0.1,1$, or $10 \mu \mathrm{M})$ in the presence and absence of $\mathrm{H}$ ASDs (50 $\mu \mathrm{g} / \mathrm{mL})$ for $24 \mathrm{~h}$. The final media volume was $0.7 \mathrm{~mL}$ (12-well plates) and $0.07 \mathrm{~mL}$ (96-well plates). The releases of IL-6 and IL-8 in the culture supernatants (50 $\mu \mathrm{L}$ ) were 
evaluated by ELISA.

Quantitation of inflammatory proteins in the culture supernatants

After exposure, the medium was harvested and centrifuged at $400 \mathrm{~g}$ for $5 \mathrm{~min}$ to remove floating cells. The final supernatants were stored at $-80^{\circ} \mathrm{C}$ until analysis. The levels of IL-6 and IL-8 (Thermo Scientific, Waltham, MA) in the culture medium were measured by ELISA according to the manufacturer's instructions. Absorbance was measured on an iMark Microplate Absorbance Reader (Bio-Rad Laboratories, Hercules, CA) with the wavelength set at $450 \mathrm{~nm}$ and a reference wavelength at 550 or $630 \mathrm{~nm}$. The detection limits of IL-6 and IL-8 were $<1 \mathrm{pg} / \mathrm{mL}$ and $<2 \mathrm{pg} / \mathrm{mL}$, respectively.

\section{FACS analysis}

For the FACS analysis, the following monoclonal antibodies were used: Mouse BD Fc Block $^{\mathrm{TM}}$ purified anti-mouse CD16/CD32 (Becton Dickinson), CD86 (GL-1, PE-conjugated, Becton Dickinson), Rat IgG2a, к Isotype Control (R35-95, PE-conjugated, Becton Dickinson), DEC205 (NLDC-145, PE-conjugated, BioLegend, San Diego, CA), Rat IgG2a, $\kappa$ Isotype Control (RTK2758, PE-conjugated, BioLegend), Hamster Anti-Mouse TCR- $\beta$ Chain (H57-597,

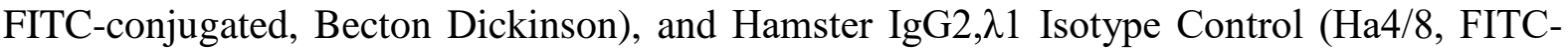
conjugated, Becton Dickinson). 
After exposure, the cells were resuspended in $50 \mu \mathrm{L}$ phosphate-buffered saline with 0.3\% bovine serum albumin and $0.05 \%$ sodium azide (Wako Pure Chemical Industries, Osaka, Japan) and then incubated with a 0.1-1 $\mu$ g amount of each antibody for 45 min at $4^{\circ} \mathrm{C}$. After incubation, the cells were washed, and the fluorescence was measured by a FACS Calibur (Becton Dickinson). For each sample, fluorescence data from approx. 10,000 cells were collected, and the number of positive cells expressed as \% events.

\section{Cell proliferation}

The cell proliferation was measured with a Cell-Proliferation-ELISA Kit (Roche Molecular Biochemicals, Mannheim, Germany) according to the manufacturer's instructions. This technique is based on the incorporation of the pyrimidine analogue BrdU instead of thymidine into the DNA of proliferating cells. BrdU incorporated into DNA is measured by a sandwich-type enzyme immunoassay using monoclonal anti-BrdU antibodies. After exposure, the cell proliferation was measured by adding BrdU to each well $20 \mathrm{~h}$ before the measurement. Absorbance was measured on an iMark Microplate Absorbance Reader with the wavelength set at $450 \mathrm{~nm}$ and a reference wavelength at $630 \mathrm{~nm}$.

\section{Statistical analysis}

Data are presented as the mean \pm standard error of the mean (S.E.M.) for each 
experimental group $(n=4)$. Differences among groups were analyzed using the Tukey multiple comparison test (Excel Statistics 2010, Social Survey Research Information, Tokyo). A p-value $<0.05$ was considered significant.

\section{Results}

Effects of B.ad and BaP in the presence and absence of H-ASDs on APCs

To determine the effects of exposure to B.ad and $\mathrm{BaP}$ in the presence and absence of $\mathrm{H}$ ASDs on the maturation and activation of APCs, we analyzed the expression patterns of CD86 (Fig. 1) and DEC205 (Fig. 2) on APCs at $24 \mathrm{~h}$ after exposure.

B.ad in both the presence and absence of H-ASDs significantly increased the expression of CD86 in a dose-dependent manner compared to the corresponding control ( $p<0.05$ vs. B.ad $0 \mu \mathrm{g} / \mathrm{mL}$ and $p<0.05$ vs. B.ad $0 \mu \mathrm{g} / \mathrm{mL}$ with H-ASDs). H-ASDs alone slightly increased the expression of CD86 compared to the controls ( $p<0.05$ vs. B.ad $0 \mu \mathrm{g} / \mathrm{mL}$ ). B.ad at a dose of 1 $\mu \mathrm{g} / \mathrm{mL}$ with H-ASDs elevated the CD86 expression at the same dose compared to B.ad alone $(p<0.05)$.

$\mathrm{BaP}$ alone at the dose of 1 or $10 \mu \mathrm{M}$ significantly increased the expression of CD86 compared to the control ( $p<0.05$ vs. BaP $0 \mu \mathrm{M})$. BaP at the dose of $0.1,1$ or $10 \mu \mathrm{M}$ with $\mathrm{H}$ ASDs also significantly increased the expression of CD86 compared to $\mathrm{BaP} 0 \mu \mathrm{M}$ with $\mathrm{H}$ ASDs $(p<0.05)$. BaP at the dose of $0.1 \mu \mathrm{M}$ with $\mathrm{H}$-ASDs elevated the CD86 expression at the 
same dose compared to $\mathrm{BaP}$ alone $(p<0.05)$.

The increases in CD86 expression induced by B.ad were higher than those induced by $\mathrm{BaP}$ in both the presence and absence of H-ASDs.

B.ad in both the presence and absence of H-ASDs significantly increased the expression of DEC205 in a dose-dependent manner compared to the corresponding control ( $p<0.05$ vs. B.ad $0 \mu \mathrm{g} / \mathrm{mL}$ and $p<0.05$ vs. B.ad $0 \mu \mathrm{g} / \mathrm{mL}$ with H-ASDs). H-ASDs alone slightly increased the expression of DEC205 compared to the control ( $p<0.05$ vs. B.ad $0 \mu \mathrm{g} / \mathrm{mL}$ ).

In contrast, the BaP treatment resulted in no significant elevation of DEC205 in the presence or absence of H-ASDs compared to the corresponding control. H-ASDs alone slightly increased the expression of DEC205 compared to the control ( $p<0.05$ vs. $\mathrm{BaP} 0 \mu \mathrm{M}$ ). $\mathrm{BaP}$ at the dose of 0.1 or $10 \mu \mathrm{M}$ with H-ASDs increased the DEC205 expression at the same dose compared to $\mathrm{BaP}$ alone $(p<0.05)$.

The DEC205 expression induced by B.ad was higher than that induced by BaP in both the presence and absence of H-ASDs,

Effects of B.ad and BaP in the presence and absence of H-ASDs on splenocytes

To determine the effects of exposure to B.ad or $\mathrm{BaP}$ in the presence and absence of $\mathrm{H}$ ASDs on the activation of $\mathrm{T}$ cells, we analyzed the proliferation and TCR expression of splenocytes at 24 and $72 \mathrm{~h}$ after exposure (Tables 1, 2). B.ad resulted in no significant elevation 
of the proliferation in the presence or absence of H-ASDs compared to the corresponding control. H-ASDs alone significantly decreased the proliferation compared to the control ( $p<0.05$ vs. B.ad $0 \mu \mathrm{g} / \mathrm{mL}$ ). B.ad at the dose of 5 or $25 \mu \mathrm{g} / \mathrm{mL}$ with H-ASDs decreased the proliferation at the same dose compared to B.ad alone $(p<0.05)$. B.ad in both the presence and absence of H-ASDs resulted in no apparent increase in TCR expression.

No change was caused by BaP in the presence or absence of H-ASDs (Table 2).

Effects of B.ad and BaP in the presence and absence of H-ASDs on airway epithelial cells

To evaluate whether B.ad or $\mathrm{BaP}$ in the presence or absence of H-ASDs induce proinflammatory responses via IL-6 and IL-8 on airway epithelial cells, we examined the production of IL-6 and IL-8 at $24 \mathrm{~h}$ after exposure (Tables 3, 4).

B.ad in both the presence and absence of H-ASDs did not cause a pro-inflammatory response via IL-6 (Table 3). B.ad in the presence of H-ASDs partially decreased the IL-6 release compared to B.ad $0 \mu \mathrm{g} / \mathrm{mL}$ with H-ASDs $(p<0.05)$. In the IL-8 analysis, no change was caused by B.ad in the presence or absence of H-ASDs.

On the other hand, BaP alone did not cause pro-inflammatory responses via IL-6 (Table 4), but it partially decreased the IL-6 release compared to the control ( $p<0.05$ vs. BaP $0 \mu \mathrm{M})$. $\mathrm{BaP}$ at the dose of 1 or $10 \mu \mathrm{M}$ with H-ASDs increased the IL-6 release compared to BaP at 0 $\mu \mathrm{M}$ with H-ASDs $(p<0.05)$. However, the pro-inflammatory impact was very small. H-ASDs 
alone decreased the IL-6 release compared to the control ( $p<0.05$ vs. BaP $0 \mu \mathrm{M})$. BaP at the dose of 0.1 or $1 \mu \mathrm{M}$ with $\mathrm{H}$-ASDs increased the IL-6 release at the same dose compared to BaP alone $(p<0.05)$.

$\mathrm{BaP}$ in the presence or absence of $\mathrm{H}$-ASDs did not cause pro-inflammatory responses via IL-8. Both exposed groups showed a partially decreased IL-8 release compared to the corresponding control ( $p<0.05$ vs. $\mathrm{BaP} 0 \mu \mathrm{M}$ or $\mathrm{BaP} 0 \mu \mathrm{M}$ with $\mathrm{H}$-ASDs). H-ASDs alone increased the IL-8 release compared to the control ( $p<0.05$ vs. BaP $0 \mu \mathrm{M}$ ). BaP at $10 \mu \mathrm{M}$ with H-ASDs decreased the IL-8 release at the same dose compared to BaP alone $(p<0.05)$.

\section{Discussion}

We observed that the exposure of APCs to B.ad in both the presence and absence of $\mathrm{H}$ ASDs increased the expression of both CD86 and DEC205. The exposure of APCs to BaP in the presence and the absence of H-ASDs increased the expression of CD86. B.ad showed greater effects than BaP on APCs in both the presence and absence of H-ASDs. There were no remarkable effects on the activation of splenocytes or the pro-inflammatory responses in the airway epithelial cells.

CD86 on APCs is the ligand for CD28 on the cell surface of T cells. The binding of CD86 with CD28 is a costimulatory signal for the activation of T cells [Chen 2004]. It has been shown that elevated CD86 expression is correlated with the development of allergic disease 
and asthma [Lombardi et al. 2010]. In our present experiments, both B.ad and BaP in both the presence and the absence of H-ASDs increased the CD86 expression on APCs. Our findings are the first to reveal that B.ad alone and co-exposure to B.ad and H-ASDs activated CD86 expression.

It was also suggested that the other types of fungi such as Candida albicans and Aspergillus fumigatus increase the CD86 expression on APCs [Grazziutti et al. 2001]. BaP in the presence of rat liver S9 homogenate and tetrachlorodibenzo-para-dioxin (TCDD) as representative PAHs were reported to induce CD86 expression on APCs [Chipinda et al. 2011; Vogel et al. 2013]. Therefore, B.ad as a fungus or BaP as a PAH can enhance the antigenpresenting ability via CD86 expression on APCs. In addition, the expression of CD86 on APCs has been reported to be regulated by NF-кB [Janeway and Medzhitov 2002].

Lin et al. [2009] indicated that the protein derived from fungi induces CD86 on human monocyte-derived dendritic cells by the NF- $\kappa$ B and MAPK pathways. Vogel et al. [2013] reported that the enhanced maturation of APCs by TCDD is associated with elevated levels of CD86 and an increased aryl hydrocarbon receptor-dependent nuclear accumulation of NF- $\mathrm{B}$ RelB. Therefore, the increased expression of CD86 caused by exposure to B.ad or BaP may be related to intracellular mechanisms such as the involvement of NF-kB signal transduction pathways.

DEC205 is a member of the C-type lectin receptor (CLR) family. This molecule is 
known to mediate the capture and internalization of ligands for subsequent processing and presentation by APCs [Jiang et al. 1995]. We previously demonstrated that flying Asian sand dust particles elevated the DEC205 expression on APCs [Honda et al. 2014]. In brief, that study obtained evidence that components of ASDs could contribute to the maturation and activation of APCs. In the present study, we observed for the first time that B.ad in the presence or absence of H-ASDs activated APCs via DEC205. These present findings are in accord with those of our previous study from the point of view that components of ASDs activate APCs.

Many studies have shown that fungi activate members of the CLR family on APCs. For example, CLR family members Dectin-1, Dectin-2 and macrophage mannose receptor (MMR) recognize $\beta$-glucans, high-mannose structures and branched $\mathrm{N}$-linked mannans of fungi, respectively [Romani 2011; Dambuza and Brown 2015]. These CLRs are important for fungal recognition and for the induction of immune responses. It has also been reported that Dectin-2 promotes house dust mite-induced T-helper type 2 and type 17 cell differentiation and allergic airway inflammation in mice [Norimoto et al. 2014]. The CLR family member DEC205 may thus also contribute to the enhancing effects of B.ad in the presence or absence of H-ASDs on allergic responses or diseases.

$\mathrm{BaP}$ in the presence and the absence of H-ASDs did not cause a significant increase in the DEC205 expression in the present experiments compared to the corresponding control (BaP $0 \mu \mathrm{M}$ or $\mathrm{BaP} 0 \mu \mathrm{M}$ with $\mathrm{H}$-ASDs). However, $\mathrm{BaP}$ in the presence of $\mathrm{H}$-ASDs partially elevated 
the DEC205 expression compared to BaP alone. It was reported that carbon black nanoparticles promoted the maturation, activation and function of DEC205 on APCs [Koike et al. 2008]. In present experiment, sand particles themselves may weakly affect DEC205 expression, and the immunological responses via DEC205 by BaP with H-ASDs mainly reflect the effects of sand particles, i.e., H-ASDs.

We observed herein that the maturation and activation of APCs induced by B.ad was higher than that induced by BaP. It is thought that B.ad can act as not only a positive adjuvant but also as an allergen. He et al. [2012, 2015, 2016] suggested that co-exposure to H-ASDs and B.ad affects lung eosinophilia via marked increases in pro-inflammatory mediators in the presence or absence of OVA as an allergen. Indeed, our present results also showed that B.ad with H-ASDs contributes to the expression of DEC205, which mediates the capture and internalization of ligands.

However, it was reported that BaP exacerbates OVA-, mite-, and Japanese cedar polleninduced allergic responses [Kanoh et al. 1996; Kadkhoda et al. 2004, 2005; Mizutani et al. 2007]. BaP alone has not elevated allergen-specific IgE [Kadkhoda et al. 2004, 2005]. There is thus a possibility that B.ad has significant direct and indirect effects on the immune response as an adjuvant and an allergen, respectively, whereas $\mathrm{BaP}$ can function mainly as an adjuvant. Therefore, B.ad may have greater effects than BaP.

In the present study, materials related to ASDs other than sand particles exaggerated 
immune responses through the activation of APCs. Regarding diesel exhaust particles (DEPs), organic chemicals rather than the carbonaceous nuclei of DEPs were reported to exaggerate allergic airway inflammation, possibly through the enhancement of Th2 responses in vivo [Yanagisawa et al. 2006]. In immune cells, DEPs act on immature APCs and enhance their antigen-presenting activity, and the action may be mediated chiefly by the organic compounds rather than by the residual carbonaceous particles of DEPs [Koike and Kobayashi 2005]. These results are in accord with our findings regarding ASDs; that is, that materials related to the particles have greater effects than the particles themselves. The organic chemical components on/in DEPs and biological components on/in ASDs may be critical for the exacerbation of respiratory and immune diseases.

Although flying ASDs caused a pro-inflammatory response via IL-6 and IL-8 production from airway epithelial cells, induced the maturation and activation of APCs, and elevated the proliferation of splenocytes [Honda et al. 2014], we observed no remarkable effects of B.ad or $\mathrm{BaP}$ in the presence or absence of $\mathrm{H}$-ASDs on the activation and pro-inflammatory responses in splenocytes and airway epithelial cells respectively in the present investigation. Many studies have reported that ASDs provide various biological and chemical materials [Ho et al. 2005; Lee et al. 2009; Maki et al. 2008, 2010; Mori et al. 2002, 2003; Tamamura et al. 2007; Wu et al. 2004; Yeo and Kim 2002]. Endotoxin is one of the components related to ASDs and the outer membrane of gram-negative bacteria, which are associated with an increase of 
respiratory diseases [Douwes et al. 2003]. Moreover, it was indicated that co-exposure to $\mathrm{SO}_{4}{ }^{2-}$ and ASDs enhanced inflammatory responses [Ichinose et al. 2005] and that organic chemicals containing various PAHs with H-ASDs in the presence of OVA increased eosinophils, lymphocytes and goblet cells in the airway compared to H-ASD exposure [Ren et al. 2014]. Materials other than B.ad and BaP may thus influence airway epithelial cells and splenocytes. In conclusion, exposure to B.ad or BaP induced the maturation and activation of APCs via CD86 or DEC205 regardless of the presence or absence of sand particles (Fig.3). B.ad showed greater effects than BaP. These results suggest that B.ad rather than BaP related to ASDs contributes to the exacerbation of respiratory and immune diseases such as asthma, especially by the activation of costimulatory molecules and recognition of xenobiotics by APCs. On the other hand, there were no remarkable effects on the activation of splenocytes or IL-6 and IL-8 release from airway epithelial cells. Because frying ASDs promoted these events, further investigations are needed to understand the contribution of other components.

\section{Acknowledgments}

This study was supported by the Environmental Research and Technology Development Fund (5-1457) of the Ministry of the Environment, Japan. We thank Dr. F. Kobayashi and Dr. Maki T. Ishikawa, Kanazawa University, for kindly providing B.ad. 


\section{Reference}

Chen L. 2004. Co-inhibitory molecules of the B7-CD28 family in the control of T-cell immunity. Nat. Rev. Immunol. 4: 336-347.

Chen YS, Sheen PC, Chen ER, Liu YK, Wu TN, Yang CY. 2004. Effects of Asian dust storm events on daily mortality in Taipei, Taiwan. Environ. Res. 95: 151-155. Doi:10.1016/j.envres.2003.08.008.

Chipinda I, Ruwona TB, Templeton SP, Siegel PD. 2011. Use of the human monocytic leukemia THP-1 cell line and co-incubation with microsomes to identify and differentiate hapten and prohapten sensitizers. Toxicology 280:135-143. doi: 10.1016/j.tox.2010.12.004.

Dambuza IM and Brown GD. 2015 C-type lectins in immunity: recent developments. Curr. Opin. Immunol. 32:21-27. doi: 10.1016/j.coi.2014.12.002.

Douwes J, Thorne P, Pearce N, Heederik D. 2003. Bioaerosol health effects and exposure assessment: progress and prospects. Ann. Occup. Hyg. 47: 187-200. Doi: 10.1093/annhyg/meg032.

Esmaeil N, Gharagozloo M, Rezaei A, Grunig G. 2014. Dust events, pulmonary diseases and immune system. Am. J. Clin. Exp. Immunol. 3:20-29.

Grazziutti M, Przepiorka D, Rex JH, Braunschweig I, Vadhan-Raj S, Savary CA. 2001. Dendritic cell-mediated stimulation of the in vitro lymphocyte response to Aspergillus. Bone Marrow Transplant.27:647-652.

Hashizume M, Ueda K, Nishiwaki Y, Michikawa T, Onozuka D. 2010. Health effects of Asian dust events: a review of the literature. Nihon Eiseigaku Zasshi 65:413-421.

He M, Ichinose T, Yoshida S, Yamamoto S, Inoue K, Takano H, Yanagisawa R, Nishikawa M, Mori I, Sun G, Shibamoto T. 2012. Asian sand dust enhances murine lung inflammation caused by Klebsiella pneumoniae. Toxicol. Appl. Pharmacol. 258: 237-247. Doi:10.1016/j.taap.2011.11.003.

He M, Ichinose T, Song Y, Yoshida Y, Kobayashi F, Maki T, Yoshida S, Takano H, Shibamoto T, Sun G. 2015. The Role of Toll-Like Receptors and Myeloid Differentiation Factor 88 in Bjerkandera adusta-Induced Lung Inflammation. Int. Arch. Allergy Immunol. 168:96-106. doi: $10.1159 / 000441895$.

He M, Ichinose T, Liu B, Song Y, Yoshida Y, Kobayashi F, Maki T, Yoshida S, Nishikawa M, Takano H, Sun G. 2016. Silica-carrying particulate matter enhances Bjerkandera adustainduced murine lung eosinophilia. Environ. Toxicol. 31:93-105.

Hiyoshi K, Ichinose T, Sadakane K, Takano H, Nishikawa M, Mori I, Yanagisawa R, Yoshida S, Kumagai Y, Tomura S, Shibamoto T. 2005. Asian sand dust enhances ovalbumininduced eosinophil recruitment in the alveoli and airway of mice. Environ. Res. 99: 361368. Doi:10.1016/j.envres.2005.03.008.

Ho HM, Rao CY, Hsu HH, Chiu YH, Liu CM, Chao HJ. 2005. Characteristics and determinants of ambient fungal spores in Hualien, Taiwan. Atmos. Environ. 39: 5839 - 5850. 
Doi:10.1016/j.atmosenv.2005.06.034.

Honda A, Matsuda Y, Murayama R, Tsuji K, Nishikawa M, Koike E, Yoshida S, Ichinose T,

Takano H. 2014. Effects of Asian sand dust particles on the respiratory and immune system.

J. Appl. Toxicol. 34:250-257. doi: 10.1002/jat.2871.

Ichinose T, Nishikawa M, Takano H, Sera N, Sadakane K, Mori I, Yanagisawa R, Oda T,

Tamura H, Hiyoshi K, Quan H, Tomura S, Shibamoto T. 2005. Pulmonary toxicity induced by intratracheal instillation of Asian yellow dust (Kosa) in mice. Environ. Toxicol. Pharmacol. 20: 48-56. Doi:10.1016/j.etap.2004.10.009.

Ichinose T, Sadakane K, Takano H, Yanagisawa R, Nishikawa M, Mori I, Kawazato H, Yasuda A, Hiyoshi K, Shibamoto T. 2006. Enhancement of mite allergen-induced eosinophil infiltration in the murine airway and local cytokine/chemokine expression by Asian sand dust. J. Toxicol. Environ. Health A 69: 1571-1585. Doi: 10.1080/15287390500470833.

Janeway CA Jr and Medzhitov R. 2002. Innate immune recognition. Annu. Rev. Immunol. 20:197-216.

Jiang W, Swiggard WJ, Heufler C, Peng M, Mirza A, Steinman RM, Nussenzweig MC. 1995. The receptor DEC-205 expressed by dendritic cells and thymic epithelial cells is involved in antigen processing. Nature 375: 151-155. Doi:10.1038/375151a0.

Kadkhoda K, Pourpak Z, Akbar Pourfathallah A, Kazemnejad A. 2004. The ex vivo study of synergistic effects of polycyclic aromatic hydrocarbon, benzo(a)pyrene with ovalbumin on systemic immune responses by oral route. Toxicology 199:261-265.

Kadkhoda K, Pourfathollah AA, Pourpak Z, Kazemnejad A. 2005. The cumulative activity of benzo(a)pyrene on systemic immune responses with mite allergen extract after intranasal instillation and ex vivo response to ovalbumin in mice. Toxicol. Lett. 157:31-39.

Kanatani KT, Ito I, Al-Delaimy WK, Adachi Y, Mathews WC, Ramsdell JW. 2010. Desert dust exposure is associated with increased risk of asthma hospitalization in children. Am. J. Respir. Crit. Care Med. 182: 1475-1481. Doi:10.1164/rccm.201002-0296OC.

Kanoh T, Suzuki T, Ishimori M, Ikeda S, Ohasawa M, Ohkuni H, Tunetoshi Y. 1996. Adjuvant activities of pyrene, anthracene, fluoranthene and benzo(a)pyrene in production of antiIgE antibody to Japanese cedar pollen allergen in mice. J. Clin. Lab. Immunol.48:133-147. Kobayashi F, Kodanikuchi K, Kakikawa M, Maki T, Yamada M, Tobo Y, Hong CS, Matsuki A, Iwasaka Y. 2010. Direct samplings, separated culture, and identifications of kosa bioaerosols over Noto Peninsula, Suzu City (Japanese). Earozoru Kenkyu. 25:23-28.

Koike E, Kobayashi T. 2005. Organic extract of diesel exhaust particles stimulates expression of Ia and costimulatory molecules associated with antigen presentation in rat peripheral blood monocytes but not in alveolar macrophages. Toxicol. Appl. Pharmacol. 209: 277285.

Koike E, Takano H, Inoue K, Yanagisawa R, Kobayashi T. 2008. Carbon black nanoparticles promote the maturation and function of mouse bone marrow-derived dendritic cells. 
Chemosphere 73: 371-376. Doi:10.1016/j.chemosphere.2008.05.054.

Kwon HJ, Cho SH, Chun Y, Lagarde F, Pershagen G. 2002. Effects of the Asian dust events on daily mortality in Seoul, Korea. Environ. Res. 90: 1-5. Doi:10.1006/enrs.2002.4377.

Lee S, Choi B, Yi SM, Ko G. 2009. Characterization of microbial community during Asian dust events in Korea. Sci. Total Environ. 407: 5308-5314. Doi:10.1016/j.scitotenv.2009.06.052.

Lin YL, Liang YC, Tseng YS, Huang HY, Chou SY, Hseu RS, Huang CT, Chiang BL. 2009. An immunomodulatory protein, Ling Zhi-8, induced activation and maturation of human monocyte-derived dendritic cells by the NF-kappaB and MAPK pathways. J. Leukoc. Biol. 86:877-889. doi: 10.1189/jlb.0708441.

Lombardi V, Singh AK, Akbari O. 2010. The role of costimulatory molecules in allergic disease and asthma. Int Arch Allergy Immunol. 151:179-189. doi: 10.1159/000242355.

Lutz MB, Kukutsch N, Ogilvie AL, Rössner S, Koch F, Romani N, Schuler G. 1999. An advanced culture method for generating large quantities of highly pure dendritic cells from mouse bone marrow. J. Immunol. Methods 223: 77-92. Doi:10.1016/S00221759(98)00204-X.

Maki T, Susuki S, Kobayashi F, Kakikawa M, Tobo Y, Yamada M, Higashi T, Matsuki A, Hong C, Hasegawa H, Iwasaka Y. 2010. Phylogenetic analysis of atmospheric halotolerant bacterial communities at high altitude in an Asian dust (KOSA) arrival region, Suzu City. Sci. Total Environ. 408: 4556-4562. Doi:10.1016/j.scitotenv.2010.04.002.

Maki T, Susuki S, Kobayashi F, Kakikawa M, Yamada M, Higashi T, Chen B, Shi G, Hong C, Tobo Y, Hasegawa H, Ueda K, Iwasaka Y. 2008. Phylogenetic diversity and vertical distribution of a halobacterial community in the atmosphere of an Asian dust (KOSA) source region, Dunhuang City. Air Qual. Atmos. Health 1: 81-89. Doi:10.1007/s11869008-0016-9.

Mizutani N, Nabe T, Ohtani Y, Han HY, Fujii M, Yoshino S, Hirayama T, Kohno S. 2007. Polycyclic aromatic hydrocarbons aggravate antigen-induced nasal blockage in experimental allergic rhinitis. J. Pharmacol. Sci. 105:291-297.

Mori I, Nishikawa M, Quan H, Morita M. 2002. Estimation of the concentration and chemical composition of kosa aerosols at their origin. Atomos. Environ. 36: 4569-4575. Doi: 10.1016/S1352-2310(02)00489-2.

Mori I, Nishikawa M, Tanimura T, Quan H. 2003. Change in size distribution and chemical composition of kosa (Asian dust) aerosol during long-range transport. Atomos. Environ. 37: 4253-4263. Doi:10.1016/S1352-2310(03)00535-1.

Norimoto A, Hirose K, Iwata A, Tamachi T, Yokota M, Takahashi K, Saijo S, Iwakura Y, Nakajima H. 2014. Dectin-2 promotes house dust mite-induced T helper type 2 and type 17 cell differentiation and allergic airway inflammation in mice. Am. J. Respir. Cell Mol. Biol. 51:201-209. doi: 10.1165/rcmb.2013-0522OC. 
Ogawa H, Fujimura M, Takeuchi Y, Makimura K. 2009. Is Bjerkandera adusta Important to fungus-associated chronic cough as an allergen? Eight cases' reports. J. Asthma 46:849855.

Ogawa H, Fujimura M, Takeuchi Y, Makimura K, Satoh K. 2011. Sensitization to Bjerkandera adusta enhances severity of cough symptom in patients with fungus-associated chronic cough (FACC). Med. Mycol. J. 52:205-212.

Ren Y, Ichinose T, He M, Arashidani K, Yoshida Y, Yoshida S, Nishikawa M, Takano H, Sun G, Shibamoto T. 2014. Aggravation of ovalbumin-induced murine asthma by co-exposure to desert-dust and organic chemicals: an animal model study. Environ. Health 13:83. doi: 10.1186/1476-069X-13-83.

Romani L. 2011. Immunity to fungal infections. Nat. Rev. Immunol. 11:275-288. doi: 10.1038/nri2939.

Tamamura S, Sato T, Ota Y, Wang X, Tang N, Hayakawa K. 2007. Long-range transport of polycyclic aromatic hydrocarbons (PAHs) from the eastern Asian continent to Kanazawa, Japan with Asian dust. Atmos. Environ. 41: 2580-2593. Doi:10.1016/j.atmosenv.2006.11.021.

Ueda K, Shimizu A, Nitta H, Inoue K. Long-range transported Asian Dust and emergency ambulance dispatches. Inhal. Toxicol. 2012 Oct;24(12):858-67. doi: 10.3109/08958378.2012.724729.

Vogel CF, Wu D, Goth SR, Baek J, Lollies A, Domhardt R, Grindel A, Pessah IN. 2013. Aryl hydrocarbon receptor signaling regulates NF- $\mathrm{B}$ RelB activation during dendritic-cell differentiation. Immunol. Cell Biol. 91:568-575. doi: 10.1038/icb.2013.43.

Watanabe M, Yamasaki A, Burioka N, Kurai J, Yoneda K, Yoshida A, Igishi T, Fukuoka Y, Nakamoto M, Takeuchi H, Suyama H, Tatsukawa T, Chikumi H, Matsumoto S, Sako T, Hasegawa Y, Okazaki R, Horasaki K, Shimizu E. 2011. Correlation between Asian dust storms and worsening asthma in Western Japan. Allergol. Int. 60: 267-275. Doi:10.2332_allergolint.10-OA-0239.

Wu PC, Tsai JC, Li FC, Lung SC, Su HJ. 2004. Increased levels of ambient fungal spores in Taiwan are associated with dust events from China. Atomos. Environ. 38: 4879-4886. Doi:10.1016/j.atmosenv.2004.05.039.

Yanagisawa R, Takano H, Inoue KI, Ichinose T, Sadakane K, Yoshino S, Yamaki K, Yoshikawa T, Hayakawa K. 2006. Components of diesel exhaust particles differentially affect Th1/Th2 response in a murine model of allergic airway inflammation. Clin. Exp. Allergy 36: 386-395.

Yeo HG, Kim JH. 2002. SPM and fungal spores in the ambient air of west Korea during the Asian dust (Yellow sand) period. Atomos. Environ. 36: 5437-5442. Doi:10.1016/S13522310(02)00672-6. 
Table 1. Effects of B.ad in the presence and absence of H-ASDs on the proliferation and TCR expression of splenocytes from NC/Nga mice

\begin{tabular}{|c|c|c|c|c|c|c|c|c|c|c|c|}
\hline \multirow{2}{*}{$\begin{array}{c}\text { H-ASDs } \\
(50 \mu \mathrm{g} / \mathrm{mL})\end{array}$} & \multirow{2}{*}{$\begin{array}{c}\text { B.ad. } \\
(\mu \mathrm{g} / \mathrm{mL})\end{array}$} & \multirow{2}{*}{\multicolumn{4}{|c|}{ Cell proliferation (\%) }} & \multicolumn{6}{|c|}{ TCR-positive cells (\%) } \\
\hline & & & & & & \multicolumn{3}{|c|}{$24 \mathrm{~h}$} & \multicolumn{3}{|c|}{$72 \mathrm{~h}$} \\
\hline \multirow{4}{*}{-} & 0 & 100.0 & \pm & 8.4 & & 28.6 & \pm & 2.6 & 39.3 & \pm & 3.8 \\
\hline & 1 & 83.8 & \pm & 3.7 & & 28.9 & \pm & 2.3 & 39.9 & \pm & 3.4 \\
\hline & 5 & 95.0 & \pm & 5.5 & & 29.0 & \pm & 2.6 & 40.8 & \pm & 3.8 \\
\hline & 25 & 91.5 & \pm & 2.8 & & 29.5 & \pm & 2.5 & 41.4 & \pm & 4.0 \\
\hline \multirow{4}{*}{+} & 0 & 76.6 & \pm & 4.6 & $\#$ & 29.6 & \pm & 2.8 & 40.9 & \pm & 3.9 \\
\hline & 1 & 70.1 & \pm & 4.5 & & 29.4 & \pm & 2.7 & 40.6 & \pm & 4.6 \\
\hline & 5 & 70.3 & \pm & 5.1 & $\#$ & 29.9 & \pm & 2.7 & 40.8 & \pm & 4.4 \\
\hline & 25 & 70.6 & \pm & 5.8 & \# & 29.6 & \pm & 2.3 & 42.3 & \pm & 4.3 \\
\hline
\end{tabular}

Cells were treated with the indicated concentrations for $24 \mathrm{~h}$ or $72 \mathrm{~h}$. Control was exposed to $2.5 \%$ saline. The data presented as the percentage of the proliferation of the control and as the positive cells expressed as the \% events are the mean \pm SEM of four individual cultures. ${ }^{\#} p<0.05$ vs. B.ad-exposed group at the same concentration. 
Table 2. Effects of BaP in the presence and absence of H-ASDs on the proliferation and TCR expression of splenocytes from NC/Nga mice

\begin{tabular}{|c|c|c|c|c|c|c|c|c|c|c|}
\hline \multirow{2}{*}{$\begin{array}{l}\text { H-ASDs } \\
(50 \mu \mathrm{g} / \mathrm{mL})\end{array}$} & \multirow{2}{*}{$\begin{array}{l}\mathrm{BaP} \\
(\mu \mathrm{M})\end{array}$} & \multirow{2}{*}{\multicolumn{3}{|c|}{ Cell proliferation (\%) }} & \multicolumn{6}{|c|}{ TCR-positive cells (\%) } \\
\hline & & & & & \multicolumn{3}{|c|}{$24 \mathrm{~h}$} & \multicolumn{3}{|c|}{$72 \mathrm{~h}$} \\
\hline \multirow{4}{*}{-} & 0 & 100.0 & \pm & 20.6 & 30.2 & \pm & 0.7 & 34.8 & \pm & 1.5 \\
\hline & 0.1 & 63.7 & \pm & 13.1 & 30.2 & \pm & 0.9 & 35.4 & \pm & 2.1 \\
\hline & 1 & 76.1 & \pm & 12.4 & 29.6 & \pm & 0.5 & 37.3 & \pm & 1.6 \\
\hline & 10 & 67.3 & \pm & 10.9 & 30.7 & \pm & 1.1 & 40.5 & \pm & 2.0 \\
\hline \multirow{4}{*}{+} & 0 & 89.5 & \pm & 13.4 & 28.8 & \pm & 0.8 & 34.0 & \pm & 1.6 \\
\hline & 0.1 & 62.7 & \pm & 5.4 & 28.6 & \pm & 0.8 & 35.2 & \pm & 1.3 \\
\hline & 1 & 61.9 & \pm & 7.8 & 29.0 & \pm & 0.9 & 35.5 & \pm & 1.4 \\
\hline & 10 & 64.5 & \pm & 10.5 & 29.6 & \pm & 0.8 & 39.7 & \pm & 1.1 \\
\hline
\end{tabular}

Cells were treated with the indicated concentrations for $24 \mathrm{~h}$ or $72 \mathrm{~h}$. Control was exposed to $0.1 \%$ DMSO. The data presented as the percentage of the proliferation of the control and as the positive cells expressed as the \% events are the mean \pm SEM of four individual cultures. 
Table 3. Effects of B.ad in the presence and absence of H-ASDs on the IL-6 and IL-8 released from human airway epithelial cells

\begin{tabular}{|c|c|c|c|c|}
\hline $\begin{array}{l}\text { H-ASDs } \\
(50 \mu \mathrm{g} / \mathrm{mL})\end{array}$ & $\begin{array}{c}\text { B.ad } \\
(\mu \mathrm{g} / \mathrm{mL})\end{array}$ & IL-6 (pg/mL) & & IL-8 (pg/mL) \\
\hline \multirow{4}{*}{-} & 0 & $46.0 \pm 2.8$ & & $475.9 \pm 16.8$ \\
\hline & 1 & $45.9 \pm 2.3$ & & $488.0 \pm 60.7$ \\
\hline & 5 & $49.2 \pm 1.0$ & & $432.0 \pm 46.4$ \\
\hline & 25 & $46.8 \pm 1.7$ & & $444.0 \pm 74.0$ \\
\hline \multirow{4}{*}{+} & 0 & $51.3 \pm 0.7$ & & $482.6 \pm 103.7$ \\
\hline & 1 & $43.4 \pm 1.4$ & * & $472.6 \pm 101.8$ \\
\hline & 5 & $49.3 \pm 0.8$ & & $498.7 \pm 116.7$ \\
\hline & 25 & $42.9 \pm 2.5$ & $*$ & $395.2 \pm 100.9$ \\
\hline
\end{tabular}

Cells were treated with the indicated concentrations for $24 \mathrm{~h}$. Control was exposed to $2.5 \%$ saline.

The data are the mean \pm SEM of four individual cultures. ${ }^{*} p<0.05$ vs. B.ad $0 \mu \mathrm{g} / \mathrm{mL}$. 
Table 4. Effects of BaP in the presence and absence of H-ASDs on the release of IL-6 and IL-8 from human airway epithelial cells

\begin{tabular}{|c|c|c|c|c|c|}
\hline $\begin{array}{l}\text { H-ASDs } \\
(50 \mu \mathrm{g} / \mathrm{mL})\end{array}$ & $\begin{array}{c}\mathrm{BaP} \\
(\mu \mathrm{M})\end{array}$ & IL-6 (pg/mL) & & IL-8 (pg/mL) & \\
\hline \multirow{4}{*}{-} & 0.0 & $41.5 \pm 3.5$ & & $345.7 \pm 7.4$ & \\
\hline & 0.1 & $21.9 \pm 0.8$ & $*$ & $255.2 \pm 11.8$ & $*$ \\
\hline & 1.0 & $37.6 \pm 2.1$ & & $239.6 \pm 17.2$ & $*$ \\
\hline & 10.0 & $47.7 \pm 3.5$ & & $309.5 \pm 32.4$ & \\
\hline \multirow{4}{*}{+} & 0.0 & $34.1 \pm 2.3$ & $\#$ & $451.1 \pm 28.4$ & \# \\
\hline & 0.1 & $36.8 \pm 1.3$ & \# & $283.5 \pm 4.7$ & $*$ \\
\hline & 1.0 & $51.3 \pm 2.5$ & $*$,\# & $200.6 \pm 16.2$ & * \\
\hline & 10.0 & $49.4 \pm 2.8$ & $*$ & $213.6 \pm 4.8$ & *,\# \\
\hline
\end{tabular}

Cells were treated with the indicated concentrations for $24 \mathrm{~h}$. Control was exposed to $0.1 \%$ DMSO.

The data are the mean \pm SEM of four individual cultures. ${ }^{*} p<0.05$ vs. each control (BaP $0 \mu \mathrm{M}$ or BaP $0 \mu \mathrm{M}$ with H-ASDs). ${ }^{\#} p<0.05$ vs. BaP-exposed group at the same concentration. 


\section{Figure legends}

Figure 1. Effects of B.ad and BaP in the presence and absence of H-ASDs on the CD86 expression of APCs. APCs from NC/Nga mice were treated with the indicated concentrations for $24 \mathrm{~h}$. Controls for B.ad and BaP were exposed to 2.5\% saline and 0.1\% DMSO, respectively. The data are presented as positive cells expressed as \% events, and they are the mean \pm S.E.M. of four individual cultures. ${ }^{*} p<0.05$ vs. each control. ${ }^{\#} p<0.05$ vs. the B.ad- or BaP-exposed group at the same concentration.

Figure 2. Effects of B.ad and BaP in the presence and absence of H-ASDs on the DEC205 expression of APCs. APCs from NC/Nga mice were treated with the indicated concentrations for $24 \mathrm{~h}$. Controls for B.ad and BaP were exposed to 2.5\% saline and 0.1\% DMSO, respectively. The data are presented as positive cells expressed as \% events, and they are the mean \pm S.E.M. of four individual cultures. ${ }^{*} p<0.05$ vs. each control. ${ }^{\#} p<0.05$ vs. the B.ad- or BaP-exposed group at the same concentration.

Figure 3. The scheme of the mechanism by which B.ad and BaP related to Asian sand dust particles contributes to the exacerbation of asthma 
Fig.1

B.ad

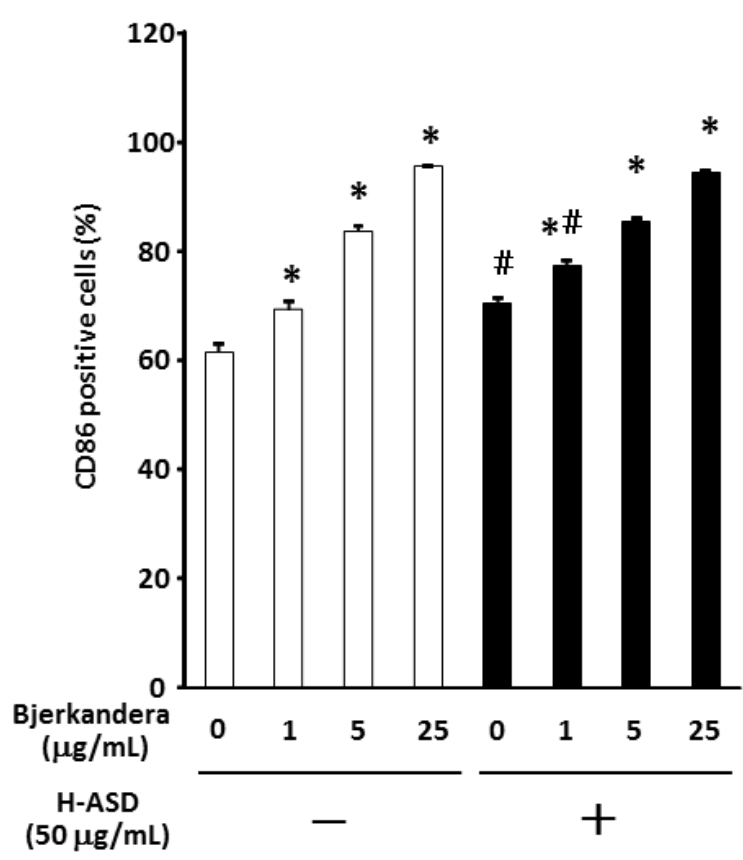

BaP

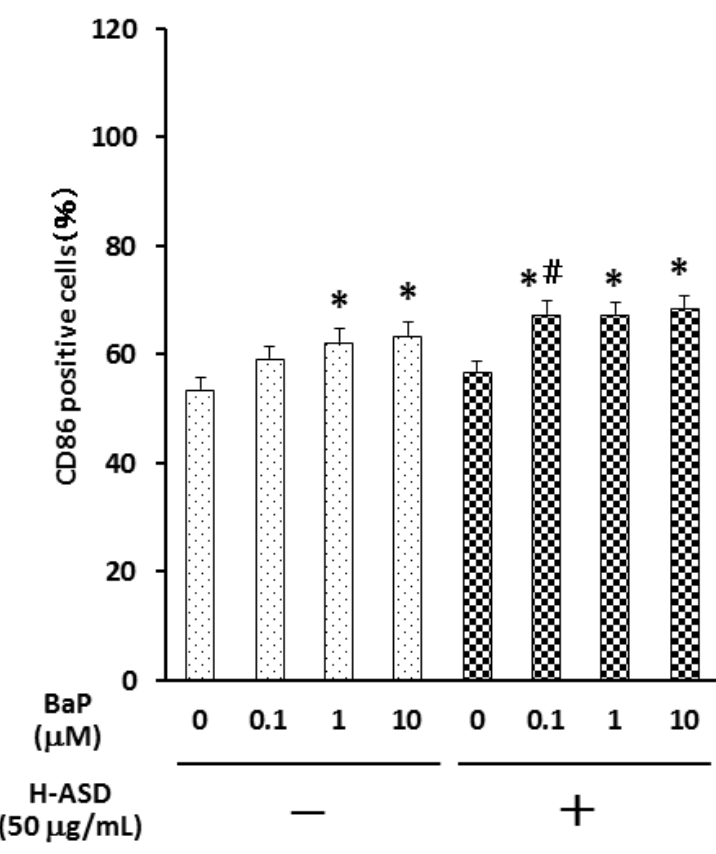


Fig.2
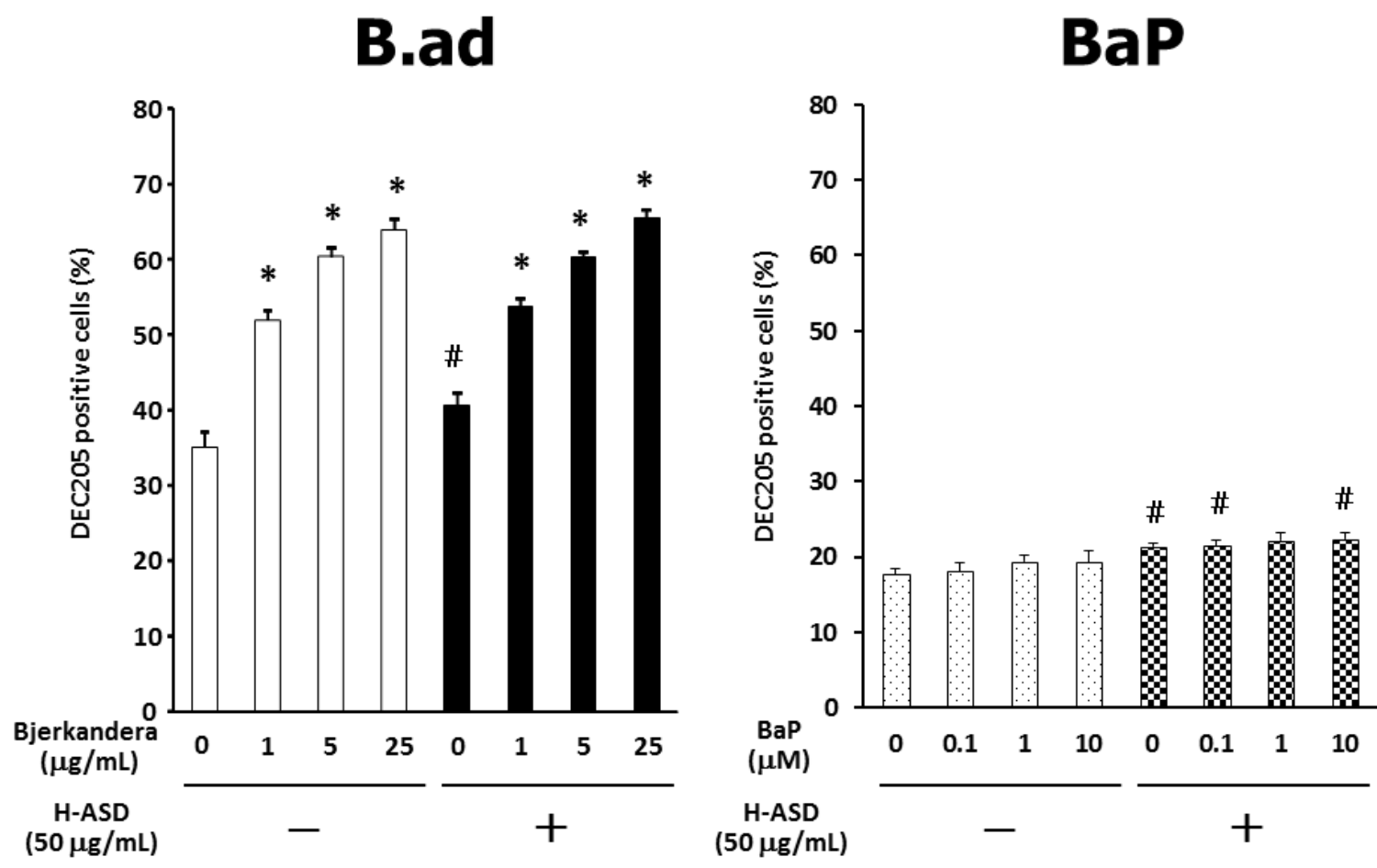
Fig.3

: Benzo[a]pyrene (BaP)

$\Delta$ _ : Bjerkandera adusta (B.ad)
: Heated Asian sand

dust particle (H-ASD)

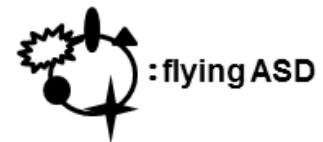

[Honda et al. 2014]

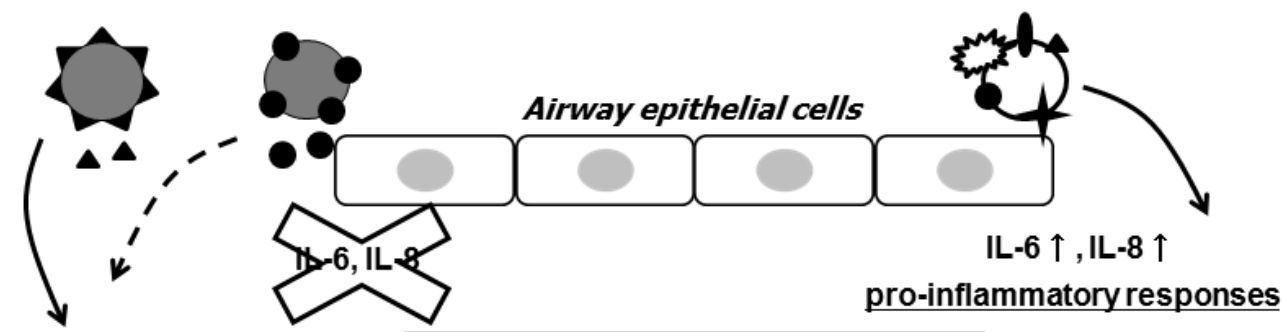

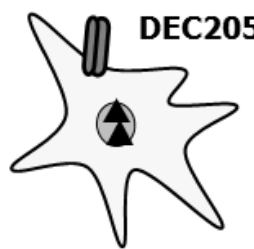

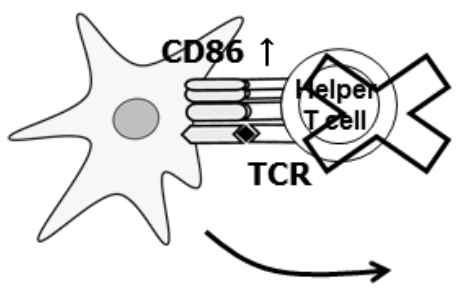

Antigen presenting cells (APCs) Uptake of xenobiotics including allergen

Antigen presentation $\downarrow$ Interaction of APCs and T cells $\downarrow$

Proliferation of lymphocytes

Exacerbation of asthma
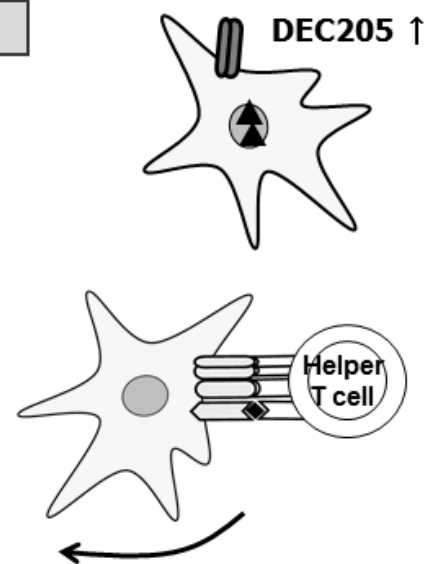